\title{
Antimicrobial Activity of Green Silver Nanoparticles against Fluconazole-resistant Candida albicans in Animal Model
}

\author{
Amira El-adly" and Iman Shabana* \\ Laser Microbiology Laboratory, National Institute of Laser Enhanced Science, Cairo \\ University, Cairo and * Faculty of Veterinary Medicine, Department of Bacteriology, \\ Immunology \& Mycology, Suez Canal University, Ismailia, Egypt.
}

\begin{abstract}
GUNGAL infections due to fluconazole-resistant Candida albicans are a serious clinical problem, requiring new efficient antifungal treatment. The present study evaluated the susceptibility of fluconazole-resistant C. albicans to green silver nanoparticles. A total of 40 isolates were examined for the expressions of CDR1, CDR2, and MDR1 gene by quantitative reverse transcription polymerase chain reaction. The antifungal activities of green silver nanoparticles alone and/or in combination with fluconazole (to improve antifungal activity) were assessed by broth microdilution assay and transmission electron microscopy. The effect of fluconazole and/or green silver nanoparticles on the production of C. albicans to protease and phospholipase was also evaluated. And finally, animal model was used to prove the safe and effective use of green silver nanoparticles in the treatment of fluconazole-resistant $C$. albicans. For all the tested C. albicans strains, the minimum inhibitory concentrations (MICs) of fluconazole and green silver nanoparticles were 64 and $4.84 \mu \mathrm{g} / \mathrm{ml}$, respectively. Green silver nanoparticles decrease the production of protease and phospholipase enzymes. The expression of both CDR1 and CDR2 were decreased after exposure to green silver nanoparticles, while the expression of CDR 1, CDR 2 and MDR 1 were all decreased when fluconazole and green silver nanoparticles were used. Green silver nanoparticles may be causing suppression of the CDR1, CDR2 and MDR1 expression in fluconazole-resistant $C$. albicans. The results suggest the use of green silver nanoparticles as a safe and effective treatment against fluconazole-resistant $C$. albicans.
\end{abstract}

Keywords: Candida albicans, Fluconazole resistance, Green silver nanoparticles.

\section{Introduction}

Oral Candidiasis is one of the common fungal infections, affecting the human oral mucosa. It is caused by Candida albicans, that is an opportunistic yeast fungus of the normal microflora in the human digestive tract. A slight change of the human immune system may support the transformation of $C$. albicans into a pathogen causing serious infections that may be lethal. Candida commonly showing asymptomatic colonization in the oral cavity, vagina, and rectum (Pfaller \& Diekema, 2004). Candida species are able to express genes to acclimatize and causing infections, they are the reason for its virulence (Chen et al., 2010). Candida colonization and pathogenicity is regarding to several virulence factors, including the expression of adhesions and invasions, morphogenetic transformation of yeast hyphae, biofilms formation, switching phenotypes and hydrolytic enzymes production (Francois et al., 2013 ). Hydrolytic enzymes are considered to be an important virulence factors. The production of these enzymes after the invasion of Candida to the host tissues destroying or disorganizing the cell membranes, causing disruption and/or dysfunction. The important hydrolytic enzymes are proteinase, that hydrolyzed the peptide bonds and phospholipase, that hydrolyzed the phospholipids (Julian et al., 2003).

Control of clinical fungal infections is complicated due to the continuous development of resistance to antifungal therapy especially in immune-compromised persons (Cowen et al., 2002). Antifungal drugs requiring prolonged use, than the prescribed for antibiotics, which is accompanied by an increase in the incidence of side effects. And the challenge is the limited number of available antifungal drugs (GomezLopez et al., 2008). Recently, the resistance of pathogenic fungi to the commercially available

"Correponding author e-mail: amiraaladly@yahoo.com

DOI: $10.21608 /$ ejbo.2018.1292.1110

C2018 National Information and Documentation Centre (NIDOC) 
fungicides is increasing and become a serious problem; therefore, finding new fungicides and alternatives is important to battle the newly emerged resistant fungal pathogens (Kanhed et al., 2014).

Azole are the main antifungal drugs of infections caused by $C$. albicans, while fluconazole-resistant Candida albicans has dramatically increased. Azole resistance has direct and indirect mechanisms. The direct mechanism involve the change of lanostero $114 \alpha$ demethylase (Kristan \& Rizner, 2012), which encoded by the ERG11 gene. The indirect mechanism is the common form of azole resistance, including over production of ATP-binding cassette transporter proteins $(\mathrm{ABC})$. $\mathrm{ABC}$ transporter proteins causing azole efflux and prevent accumulation (Prasad \& Goffeau, 2012). Multidrug resistance in $C$. albicans involved, the $\mathrm{ABC}$ transporterencoding gene CDR1 and the MFS proteinencoding locus MDR1 (Fling et al., 1991). Both CDR1 and MDR1 are localized in C. albicans plasma membrane (Kapoor et al., 2010). CDR2 is an $\mathrm{ABC}$ transporter-encoding gene, involves azole resistance in case of it's over expression or deletion of CDR1 (Sanglard et al., 1998 ).

Green silver nanoparticles (AgNPs) are an eminent antimicrobial and has a long history in medication with a well-endured tissue reaction and low toxicity. Since nano-silver has a highly toxic effect on most microorganisms, therefore it may be a good alternative for antimicrobial drugs (Herrera et al., 2000). The green synthesis techniques are synthetic methods that use relatively non-toxic solvents such as water, biological extracts (Yu, 2007). Olive plant able to reduce inorganic salts to the elemental forms and the current trials is to use olive for the reduction of silver nitrate to metallic silver. The advantage of olives is the antimicrobial cababilities against several fungi as Rhizopus, Fusarium, Rhizoctonia, Alternaria, Stemphylium (Sastry et al., 2003 and Al-Mughrabi et al., 2001). Green bio-reduction methods for the silver nanoparticles synthesis were reported by many researchers using plant extracts such as Macrotylo mauniflorum (Vidhu et al., 2011), Anacardium mushroom extract (Sheny et al., 2011), Coleus amboinicuslour (Narayanan \& Sakthivel, 2011), Medicago sativa (Lukman et al., 2011), Citrus sinensis peel (Kaviya et al., 2011), and Olea europaea (Awwad et al., 2012) etc.
In the present study, broth microdilution method, and transmission electron microscope were used to evaluate the antifungal activity of green silver nanoparticles (AgNPs) alone or combined with fluconazole on the growth of fluconazole-resistant Candida albicans strains. In addition, reverse transcription polymerase chain reaction was used to evaluate $\mathrm{CDR} 1, \mathrm{CDR} 2$, and MDR1 expression before and after the treatment. The effect of green silver nanoparticles (AgNPs) on the virulence of the isolates was also studied in animal model.

\section{Materials and Methods}

Microbial isolates and culture condition

Our study included a group of 40 clinical Candida albicans isolates were obtained from (El-Manyal Hospital, Faculty of Medicine, Cairo University) with symptoms of oral Candidiasis. In this study, isolates from patients being under antibiotic treatment, or having antifungal drugs in the last 30 days. In addition, the patients informed if they had been previously exposed to azoles at least once in the last year as treatment for oral Candidiasis. Swabs were collected from buccal mucosa and tongue by gentle rubbing on the lesion. Swabs were streaked on Sabouraud's Dextrose agar, and the isolates were identified by corn meal agar, formation of germ-tube, fermentation assimilation and the presence of thick-walled spores. The API 20 system were used to confirm the identification (bioMerieux, France) (Monroy-Perez et al., 2012 ).

\section{Detection of fluconazole resistance genes Isolation RNA}

Candida albicans isolates were added to tubes with Lysing Matrix C silica beads and homogenization was performed by FastPrep ${ }^{\circledR}-24$ homogenizer (MP Biomedicals, USA). RNeasy® Mini Kit (Qiagen, Germany) was used for RNA isolation.

\section{Complementary DNA synthesis}

cDNA was synthesized by reverse transcription of the isolated RNA, using cDNA Reverse Transcription Kit (Applied Biosystems, USA).

\section{CDR1, CDR 2 and MDR1 expression}

The expression of CDR1, CDR2 and MDR1 was evaluated by Q-PCR. Primers and Taq Man probes sequences were shown in Table 1. The reactions were done in the Applied Biosystems 7300 Real-Time PCR System (Applied 
Biosystems, USA) as the following, Ampli Taq DNA polymerase Gold $\AA 95^{\circ} \mathrm{C}, 10 \mathrm{~min} ; 95^{\circ} \mathrm{C}$, $15 \mathrm{sec} ; 60^{\circ} \mathrm{C}, 1 \mathrm{~min}$. for 40 cycles. Fluorescence was measured at a wavelength $(\operatorname{lmax}=518 \mathrm{~nm})$.

TABLE 1. Primers and probes used in the Q-PCR method.
Threshold cycles (CT) values were analyzed and compared by Relative Quantitation software (Applied Biosystems, USA).

\begin{tabular}{lcc}
\hline Primer sequence & Probe sequence & Gene \\
\hline $\begin{array}{l}\text { CCGTTTTCGGTCAACTTGTAATGG } \\
\text { AAACGATCCAGTGGTTTGACTAAGATT }\end{array}$ & ACACCGACGACAATAT & CDR1 \\
$\begin{array}{l}\text { GGCTTATCAATTTTATTCTTCACACAAATGGA } \\
\text { CAGTCAAGGCAACATAAACTCCTAAGA }\end{array}$ & ATGCAACGGTAATTCC & CDR2 \\
$\begin{array}{l}\text { AACATTATTATATCGCAAGGCTAAAAGAT } \\
\text { TCCTTCACTTGTGATTCTGTCGTT }\end{array}$ & CCGGTGATGGCTCTCA & MDR1 \\
\hline
\end{tabular}

Green silver nano-particles (AgNPs) preparation

Green silver nano-particles (AgNPs) were purchased from Chemical lab, Cairo University, Egypt, the particles were prepared by method as reported by Gavhane et al. (2012) with some modification. $50 \mathrm{~g}$ of fine cut olive leaves in $1 \mathrm{~L}$ glass beaker containing $500 \mathrm{ml}$ sterile distilled water. Mixture was boiling for $10 \mathrm{~min}$. the extract was coiled at room temperature and filtered, cooled and stored in order to used, the color of AgNPs solutions change from pale yellow to grey black indicating the reduction of silver positive ions to silver nanoparticles. The particles were spherical in shape, and about $30 \pm$ $1.0 \mathrm{~nm}$ in diameter, and optical absorption peak range at $(440-458 \mathrm{~nm})$.

Evaluation of AgNPs on the virulence of $C$. albicans

\section{Protease activity}

The Bovine serum albumin medium (BSA) was used for the protease production assay, $10 \mu \mathrm{l}$ aliquots of the Candida suspension (48 h-old Candida culture, $5 \times 10^{5}$ cells, treated with AgNPs $8 \mu \mathrm{g} / \mathrm{ml}$ alone or combined FLC/AgNPs $8 / 2.17 \mu \mathrm{g} / \mathrm{ml}$ ) was inoculated into the wells of the medium and incubated for two days at $37^{\circ} \mathrm{C}$. $20 \%$ trichloracetic acid was used for fixation, stained with $1.25 \%$ amido black and decolorized with $15 \%$ acetic acid. Agar opaqueness around the wells and absence of black color, indicating proteolysis. The diameter of unstained area referred to protease production. The protease activity $(\mathrm{Pz})$ is the ratio of the well diameter to the diameter of the unstained zone (Vidotto et al., 2004). The Pz equal 1, indicating no protease production, while a high production of protease is indicated by low Pz.

\section{Phospholipase activity}

Phospholipase production was assayed by using Egg-yolk agar medium (EYA). $10 \mu \mathrm{l}$ aliquots of the Candida suspension (48 h-old Candida culture $5 \times 10^{5}$ cells , treated with AgNPs $8 \mu \mathrm{g} / \mathrm{ml}$ or FLC/AgNPs $8 / 2.17 \mu \mathrm{g} / \mathrm{ml}$ ) was inoculated into the wells of the egg-yolk medium and incubated at $37^{\circ} \mathrm{C}$ for $48 \mathrm{~h}$. Hydrolysis of lipids resulted in the formation of a calcium complex with fatty acids, producing a precipitate around the colony. Phospholipase activity $(\mathrm{Pz}$ value) was the ratio between the diameter of the colony and the diameter of the precipitation area (Vidotto et al., 2004). When the Pz equaled 1, indicating no phospholipase production, while high production of the phospholipase is indicated by low Pz.

\footnotetext{
Antifungal activity of green silver nanoparticles (AgNps)

Minimum inhibitory concentration (MIC) of fluconazole (FLC), Sliver nanoparticles (Ag NPs) on C. albicans cells was determined by broth microdilution assay according to the National Committee for Clinical Laboratory Standards (CLSI, 2012 ) guidelines. A suspension of $C$. albicans was adjusted to $75 \%$ transmittance using a double-beam UV-visible spectrophotometer. $\mathrm{CFU} / \mathrm{ml}$ was quantified by plating of a $10 \mathrm{ml}$ suspension on SDA and colonies counting. The suspension concentration
} 
was adjusted to $5 \times 10^{5}$ cells $/ \mathrm{ml}$ using RPMI 1640 medium (Sigma). $100 \mu \mathrm{l}$ Aliquot of the suspension, were inoculated into a 96-well microdilution plate containing $100 \mu \mathrm{l}$ of dilution of $(1-10 \mu \mathrm{g} / \mathrm{ml})$ AgNPs or $(2-128 \mu \mathrm{g} / \mathrm{ml})$ of Fluconazole. The effect of combinations of FLC with nanoparticles on Candida cells was assessed. The MIC was recorded as no turbidity showed.

\section{Transmission electron microscopy (TEM)}

A suspension of $C$. albicans cells $\left(5 \times 10^{5}\right.$ cells $/ \mathrm{ml}$ ) prepared from a culture grown for $24 \mathrm{~h}$ at $37^{\circ} \mathrm{C}$ in Yeast extract peptone dextrose (YPD). Demineralized sterile water was used for cells suspension, the suspension centrifuged at 3500 rpm for $10 \mathrm{~min} .25 \mathrm{ml}$ sterile demineralized water was used for the re-suspended of the pellets. The suspension was distributed in six tubes, each containing $1 \mathrm{ml}$ suspension. Two tubes were treated with AgNPs ( $8 \mu \mathrm{g} / \mathrm{ml}$ ), and the other two tubes with combined FLC/ AgNPs (8/2.17); the last two tubes with the spore suspension in remained without treatment and was used as a control. The cells were harvested and washed in $0.1 \mathrm{M}$ sodium phosphate buffer, then prefixed with glutaraldehyde for $1 \mathrm{~h}$, and left in $1 \%$ osmium tetra oxide for $1 \mathrm{~h}$ at $4^{\circ} \mathrm{C}$. Then was washed in distilled water and dehydrated in a graded acetone series (35 to 100\%). The cells were embedded in Epon and the small blocks of samples were cut with an ultra-microtome (Leica Ultracut), then analyzed at $80 \mathrm{KV}$ using (JEOL 1010) TEM (Sangetha et al., 2009) .

Toxicity assay of the prepared AgNPs

Cell line (Hep-2 cells) were grown onto microtiter plates containing $100 \mu \mathrm{l}$ Dulbecco's modified Eagle's medium (DMEM) for $24 \mathrm{~h}$. Different concentrations (2, 5, $10 \mu \mathrm{g} / \mathrm{ml})$ of AgNPs, or combined with FLC (serial two fold dilutions of $2-128 \mu \mathrm{g} / \mathrm{ml}$ ) were added. $100 \mu \mathrm{l}$ of each concentration was inoculated into the cells and incubated at $37^{\circ} \mathrm{C}$ for $24 \mathrm{~h}$. The viable cells stained with staining buffers for 1-2 h. 33\% citric acid was used for elution, and the absorbance was measured at $595 \mathrm{~nm}$. Determination of the non-toxic concentration of the AgNPs or FLC/ AgNPs combined was done by the microscopic examination (Marcato et al., 2013).

\section{Animal model \\ Animals and experimental oral candidiasis \\ This experiment was investigate the possibility of using the combined application}

of fluconazol and green silver nanoparticles to improve antifungal activity against fluconazoleresistant Candida alicans in animal model. Animal housing and treatment conditions were approved by the ethics committee of Institutional Animal Care (IACUC), Egypt .

Forty female healthy Mice (6 weeks old) weighing between 20-25 gm were used in this study, Mice were kept in stainless steel cages under controlled temperature $\left(22 \pm 2^{\circ} \mathrm{C}\right)$, humidity was at $55 \pm 10 \%$ and $12 / 12 \mathrm{~h}$ cycle of light and dark with an access of food and drinking water. The animals were divided into four groups, ten mice each. Group (1): control group which received physiological saline solution, the other animal groups were infected with C. albicans and divided into, Group (2): Candida group (none treated), Group (3): treated with AgNPs (10 $\mu \mathrm{g} /$ $\mathrm{ml}$ ), and Group (4): treated with combined FLC/ $\operatorname{AgNPs}(8 / 2.17 \mu \mathrm{g} / \mathrm{ml})$.

Oral candidiasis in mice was induced by Candida albicans. It was prepared by harvested one colony of $C$. albicans cells in RPMI 1640 medium (UFC Biotch, KSA) and $5 \times 10^{5}$ viable cells/ml cell suspension was adjusted. The animals were immunosuppressed with subcutaneous injections of prednisolone on days 1, 5, 9 and 13 of the experiment at a dose of $100 \mathrm{mg} / \mathrm{kg}$ body weight according to the evaluated period ( $24 \mathrm{~h}$ and 7 days after treatment). Tetracycline $(0.83 \mathrm{mg} / \mathrm{mL})$ was added to the drinking water throughout the trial. On day 2, sterile swabs were soaked in C. albicans suspension and rubbed on the dorsum of the tongue of sedated animals with chlorpromazine hydrochloride $0.1 \mathrm{ml}(2 \mathrm{mg} / \mathrm{mL})$ to induce candidiasis. At day 6 , a cotton pad was used to swab the whole oral cavity, then put in a $5 \mathrm{ml}$ sterile saline and vortexes thoroughly. A serial 100 -fold dilutions of the cell suspension were plated on Sabouraud dextrose agar and incubated for at $37^{\circ} \mathrm{C} 24 \mathrm{~h}$. The growing Candida colonies were then counted (Takakura et al., 2003).

\section{Treatments and evaluation}

The infection was verified by visual examination on day 7 , the animal groups were treated daily from day 7 to 11 . The animals were anesthetized by $\mathrm{I} / \mathrm{M}$ with pentobarbital. The tongues of the animals were gently taken out of the oral cavity, AgNPs diluted in water $(10 \mu \mathrm{g} /$ $\mathrm{ml}) \&$ combined FLC/AgNPs $(8 / 2.17 \mu \mathrm{g} / \mathrm{ml})$ was 
applied by pipette on to the dorsum of the tongue of anesthetized mice using $50 \mu \mathrm{l} / \mathrm{mice}$ once a day for 5 days. The negative control group did not infected with $C$. albicans or received treatment. The control group treated with physiological solution. The microbiological evaluation was carried out every $24 \mathrm{~h}$ for 7 days after treatments to avoid the decrease of colony forming units $(\mathrm{CFU} / \mathrm{mL})$, because swabbing of the oral lesions may reduce yeast load in the local tissue.

The animal's body weight was taken in day 0 and day 11 before dissection; the body weight changes statistically analyzed using One-way ANOVA. Histological examination was done for negative and positive control group $\left(1^{\text {st }}\right.$ and $2^{\text {nd }}$ group) for comparison and evaluation. Tongue was washed by saline then natural buffered formalin. Tissue samples were taken and processed with graded alcohols and xylene, and embedded in paraffin blocks in automatic processor. Serial longitudinal sections of $4.6 \mu \mathrm{m}$ from tongue were stained with $\mathrm{H}$ and $\mathrm{E}$ for histological examination. Specimens showed various patterns of cellular activity under light microscopy.

\section{Statistical analysis}

The data were analyzed statistically using student's $\mathrm{T}$ test. $\mathrm{P}$ value of 0.05 or less was considered statistically significant (SPSS 14, 2006).

\section{Results and Discussion}

Candida albicans was identified in $75 \%$ $(\mathrm{n}=30)$ of the samples. All isolates were sensitive to nystatin, whereas $93.3 \%(\mathrm{n}=28), 86.7 \%(\mathrm{n}=26)$ were resistant to fluconazole and ketoconazole, respectively. The most resistant fluconazoleCandida albicans was taken in the further experiments (data not shown).

\section{The expression of CDR1, CDR2 and MDR1}

Table 2 showed the relative expression of CDR1, CDR2, MDR1 in C. albicans isolates before and after the treatment with $\operatorname{AgNPS}(8 \mu \mathrm{g} /$ $\mathrm{ml})$ and/or FLC/AgNPs combined $(8 / 2.17 \mu \mathrm{g} / \mathrm{ml})$. Their expression was studied using the Relative Quantitation software (RQ) (Chau et al., 2004 and Chen et al. 2010). CDR1, CDR2 and MDR1 genes are the major azole resistance determinants $(\mathrm{Hu}$ et al., 2015), their products are active transport pumps resulting in the efflux of azole from the Candid's cell (Sanglard, 2002). The data showed decreasing their relative expression after treatment with AgNPS $(\mathrm{P}>0.05)$ and combined FLC/AgNPS $(\mathrm{P}<0.05)$. A synergistic effect may be exerted between the green silver nanoparticles and fluconazole

Table 2. The relative expression of CDR1, CDR2, MDR1.

\begin{tabular}{lccc}
\hline \multirow{2}{*}{ Gene } & \multicolumn{3}{c}{ RQ (2-rrCT) mean } \\
\cline { 2 - 4 } CRD1 & Untreated & AgNPS & FLC/AgNPS \\
CDR2 & 31.2 & 28.3 & 25.1 \\
MDR1 & 0.4 & 0.3 & 0.2 \\
\hline
\end{tabular}

\section{Enzymes activity}

Enzymes are important weapons providing the pathogen the ability to invade host tissue. Candida albicans are able to produce proteinase and phospholipase enzymes which increase its virulence. In this study. The data in Table 3 showed variation in the enzyme activity after treatment with AgNPs or combined FLC/AgNPs. Treatment with AgNPs induced variable reduction in proteinase and phospholipase activity $(0.88 \&$ $0.85 \mathrm{~mm}$, respectively) in comparing with the control ( $0.659 \& 0.607$, respectively). A negative effect of AgNPs on the activities of exoenzymes, including b-glucosidase, acid phosphatase, dehydrogenase, urease and Keratinase was reported by Shin et al. (2012). The inhibitory effect of AgNPs on proteolytic enzymes activity maybe due to their preferential adsorption or attachment on the surface of enzyme (Fischer et al., 2002 and Bayraktar et al., 2006), which induces changes in function, regulation and configuration of the enzyme (Wu et al., 2009), or may possibly limit the access of substrate to the active site of the surface-bound enzyme (Bhinder \& Dadra, 2009). Moreover, it was also proposed that positive silver ions released from AgNPs can react with sulfur- 
containing proteins, resulting in the inactivation of enzyme functions (Gupta \& Silver, 1998 and Matsumura et al., 2003). Further reduction of proteolytic enzyme activity was recorded on using AgNPs in combination with floconazole. It has also been suggested that there can be release of silver ions by the nanoparticles (Feng et al., 2000) and these ions can interact with the essential serine residue at or near the active site of the proteinase and phosphlipase and resulted in the inactivation of the enzyme. In other cases, the charged silver ions may ultimately attach with the sensing surface of the C-terminal residue of amines in enzyme, causing its modification. It has to be mentioned that reduction activity, even for treatment with AgNPs alone, or combined with fluconazole were significantly higher.

TABLE 3. Effect of AgNPs and/or FLC/AgNPs combined on the activity of protease and phospholipase enzymes against fluconazole-resistant Candida albicans .

Protease Phospholipase

$\mathbf{P z}(\mathbf{m m})$

\begin{tabular}{lcc}
\hline Control & 0.659 & 0.607 \\
AgNPS & 0.88 & 0.85 \\
FLC/AgNPS & 0.92 & 0.93 \\
\hline
\end{tabular}

$\mathrm{Pz}=1$ (negative), $\mathrm{Pz}<0.9-0.99(+), \mathrm{Pz}<0.8-0.89(++), \mathrm{Pz}<0.70-0.79(+++), \mathrm{Pz}<0.70(++++)$.

\section{Antifungal activity}

Fluconazole is the drug of choice for the treatment of candidiasis. However, it has several side effects, including nausea, vomiting, and headache, liver damage (Lilly, 2012). Reports on fluconazole-resistant $C$. albicans strains have been increased in the last few years (Pfaller, 2012). Consequently, an urgent need emerges to find alternative therapies for candidiasis. So, the present study tested the green sliver nanoparticles (AgNPS) produced by Olive leaves for their effect against fluconazole-resistant $C$. albicans isolates. The MIC of AgNPs alone or in combination are shown in Table 4. Candida isolates were resistant to FLC with MIC value of $64 \mu \mathrm{g} / \mathrm{ml}$. AgNPs showed an antifungal effect with MIC value of $4.84 \mu \mathrm{g} / \mathrm{ml}$. The effect on Candida was selective, as the cytotoxic concentration of AgNPs on Hep-2 cells was higher than $10 \mu \mathrm{g} / \mathrm{ml}$ (data not shown). The combination between AgNPs and FLC had a marked reduction in FLC MIC value $(8 / 2.17 \mu \mathrm{g} /$ $\mathrm{ml})$. Our results was in accordance with Ishida et al (2014), who reported a fungicidal effect of green AgNPs on C. albicans, with MIC and MFC values of 1.68 and $3.40 \mu \mathrm{g} / \mathrm{ml}$, respectively. No cytotoxic effect was shown up to a concentration of $10 \mu \mathrm{g} / \mathrm{ml}$ of AgNPs for Hep-2 cells (Marcato et al., 2013 and Lima et al., 2013). Our results emphasize the decrease of fluconazole MIC of $C$. albicans when combined to AgNPs. The resistance to fluconazole in C. albicans is strongly associated with over expression of efflux pumps encoding genes (Odds et al., 2003). The mechanisms of Ag-NPs against $C$. albicans are not fully understood, While AgNP-treated C. albicans shows disruption of the cell wall and cytoplasmic membrane (Kim et al., 2009). Moreover, AgNPs increasing in the production of reactive oxygen species and hydroxyl radical, which causing the damage of the cell membrane (Hwang et al., 2012). Since AgNPs alters the cell membrane permeability, we may assume that they may facilitate the entry of FLC, which interferes with the biosynthesis of ergosterol (Xia et al., 2016), as the growth of the pathogenic fungus $T$. asahii was inhibited by silver. Ag penetrated the cells, damage the organelles, including mitochondria and ribosome and caused condensation and margination of chromatin, a marker of apoptotic cell death. Moreover, due to their small size, the silver nanoparticles may attach to the cell surface and get into the cells directly without damaging the cell wall and then cause the death of the cell (Xia et al., 2016) 
TABLE 4. MIC $\mu \mathrm{g} / \mathrm{ml}$ of fluconazole and/or green silver nanoparticles or fluconazole combined with green nanoparticles against fluconazole-resistant Candida albicans.

$\mathrm{MIC} \pm \mathrm{SD}$

Transmistion electron microscope (TEM)

the ultrastructure alterations or organelles changes in $C$. albicans after treatment with AgNPs and/or combined FLC/AgNPs was detected by Transmission electron microscopy. Photo (1-a ) of untreated Candida cells (control group) appeared with a uniform central density, structured nucleus, and cytoplasm with several endomembrane elements and had a regular intact cell wall and plasma membrane. On the other hand, treated Candida cells with AgNPs and/or combined FLC/AgNPs, showed cell lysis, with absence of the cell wall and ruptured cytoplasmic membrane, causing loss of intracellular material and cell wall abnormalities. Some cells showed invaginations of the cytoplasmic membrane with marked disorganization of the cytoplasm and reduction of the intracellular volume (Photo1-b-c).

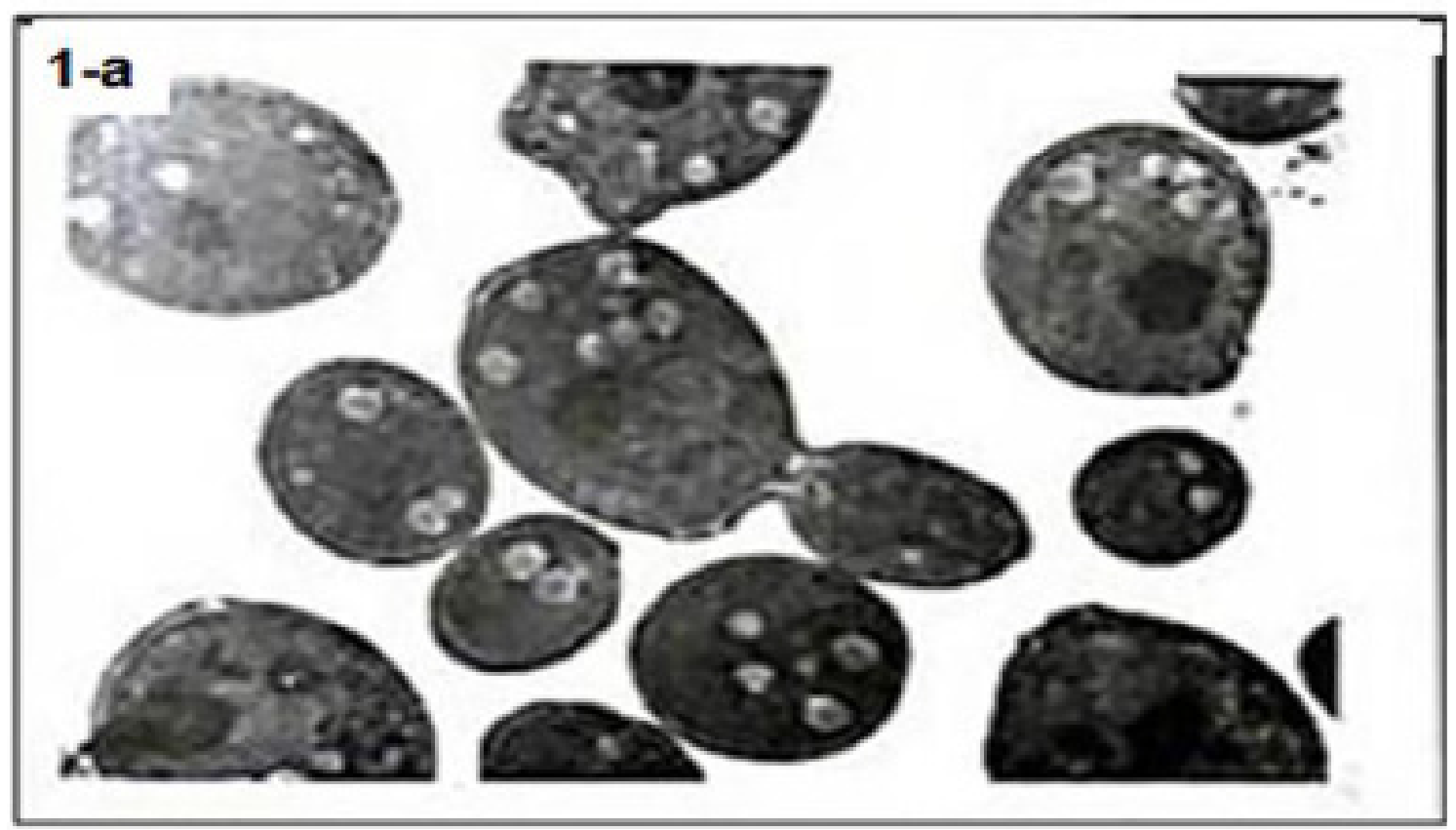

Photo 1-a. TEM micrographs of the untreated Candida albicans cells (control group). 


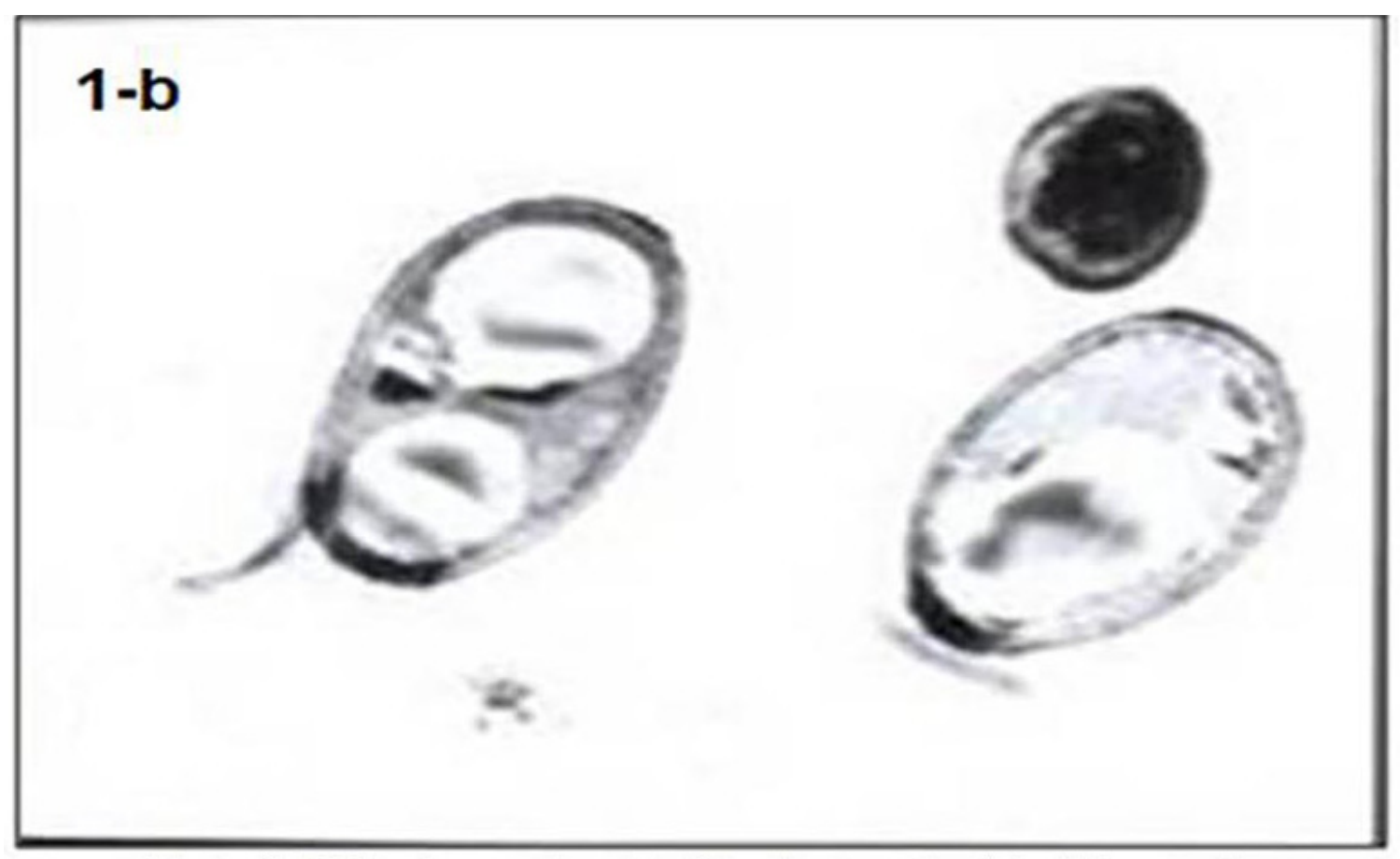

Photo 1-b. TEM micrographs of AgNPs effect on Candida albicans cells.

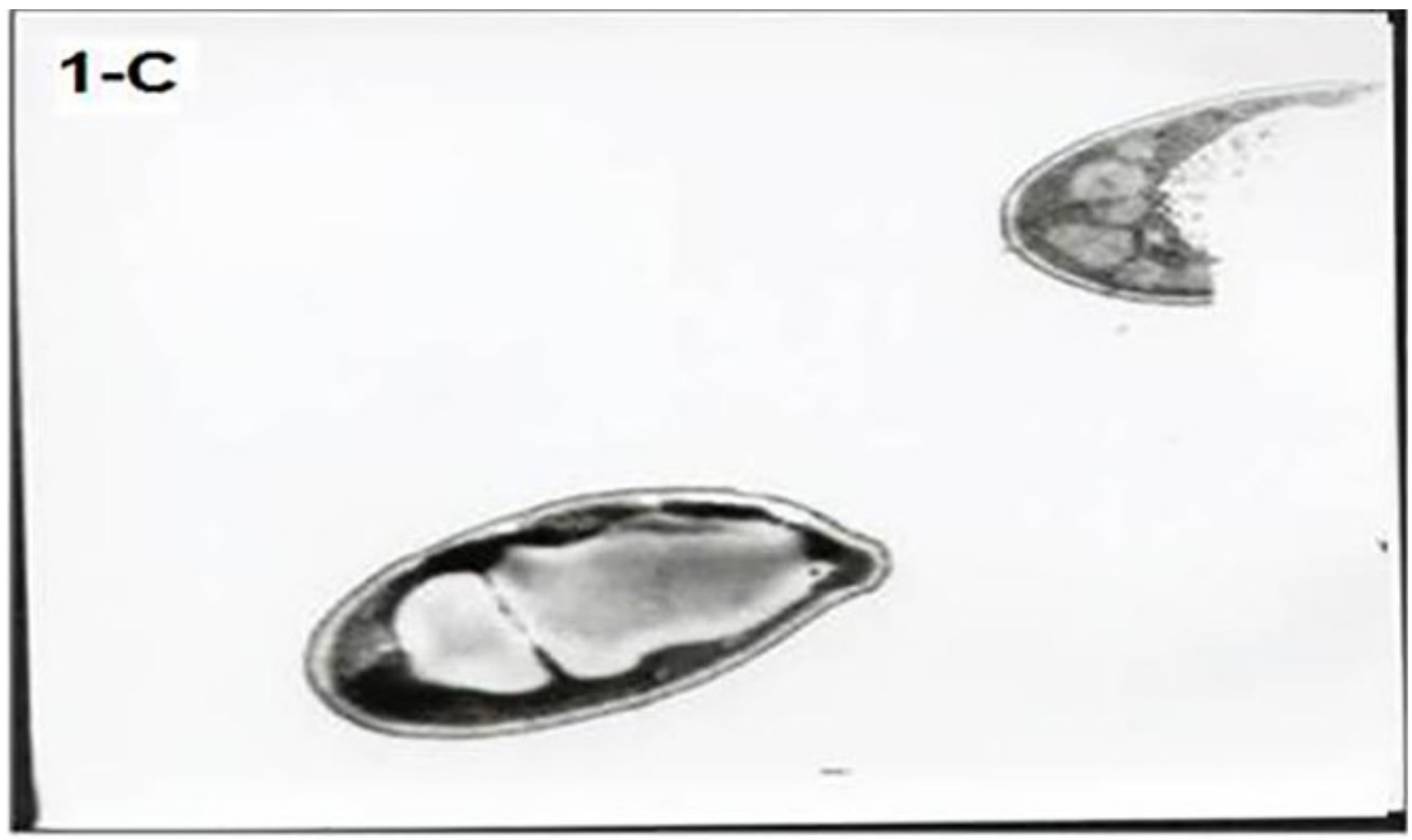

Photo 1-c. TEM micrographs of FLC/AgNPs combined effect on Candida albicans cells. 


\section{Vivo experiment}

The present investigation, used the induced oral candidiasis in immunocompromised mice as a proposed model. All animals showed white patches or pseudomembrane on the dorsum of the tongue with inflammatory infiltrate with numerous hyphae. At day 6, there was a statistically significant difference in animal's body weights, the body weight were decreased after immunosuppression with two subcutaneous injections of prednisolone. Mean and standard deviation of the body weight in infected and treated groups were calculated and showed decrease in values compared with control group. Combined FLC/AgNPs treated group showed less changes in body weight than other groups (Table 5). The body weight loss in all groups was highly significant when the result was compared with animal body weight of control group $(\mathrm{P}<0.001)$. This result was similar to the results of Solis \& Filler (2012) .

TABLE 5. The body weight of the animal groups.

\begin{tabular}{lccc}
\hline Animal group & \multicolumn{3}{c}{ Mean of body weight } \\
\cline { 2 - 4 } & Zero day & $\mathbf{5}^{\text {th }}$ day & Change in weight $(\mathbf{g})$ \\
\hline Control & 20.70 & 22.38 & 1.68 \\
Candida & 20.00 & 17.50 & $2.5-$ \\
AgNPS & 22.00 & 20.30 & $1.70-$ \\
FLC/AgNPs & 22.00 & 21.21 & $0.79-$ \\
\hline
\end{tabular}

$\mathrm{P}<0.001$

In this study, the oral candidiasis were treated after inoculation with either AgNPs or AgNps combined with fluconazole. The number of $C$. albicans cells in oral cavity before and after treatment was counted by plating Candida suspension from a cotton pad that swapped from oral cavity of animals after infection and after treatment. The control group showed no Candida cells growth while, Candida-infected group had $6.58 \log _{10} \mathrm{CFU} / \mathrm{ml}$ Candida cells (Table 6). The treated groups (Green silver nanoparticles, and combined FLC/AgNPs) showed high reduction in the number of Candida cells after treatment (2.70 $\left.\log _{10} \mathrm{CFU} / \mathrm{ml}\right)$. The treated groups showed statistically significant reduction in Candida cells count $(\mathrm{P}<0.001)$ as compared to Candidainfected group. Our results are in accordance with the finding by Maneewattanapinyo et al (2011) of safe administration of colloidal AgNPs to oral, eye and skin of the laboratory animals for short periods of time.

TABLE 6. Microbiological evaluation of Candida albicans cells number in oral cavity before and after treatment with AgNPS and/or FLC or FLC/AgNPs.

\begin{tabular}{lcc}
\hline Treated animal group & \multicolumn{2}{c}{$\log _{10} \mathbf{C F U} / \mathbf{m l}$ of candida cells \pm SD } \\
\hline & Before & After \\
\cline { 2 - 3 } Control & 0.0 & 0.0 \\
Candida & $6.58 \pm 0.08$ & $6.50 \pm 1.03$ \\
AgNPS & $6.54 \pm 0.06$ & $2.70 \pm 0.67$ \\
FLC/AgNPS & $6.57 \pm 0.07$ & $2.70 \pm 0.86$ \\
\hline
\end{tabular}


The histological examinations supported the macroscopic changes of candidiasis on the tongue dorsum after treatment. Candida penetrates vertically from the keratinized layer to the upper part of the prickle layer in the untreated group. While in the combined AgNPs /FLC-treated group, the fungal structures exposed on the tongue surface without reaching the inner layers of keratin. The elongated filiform papillae were similar to the control group. The other treated groups showed different degrees of recovered with semiformal epithelial of tongue dorsum (Photo 2- a-d).

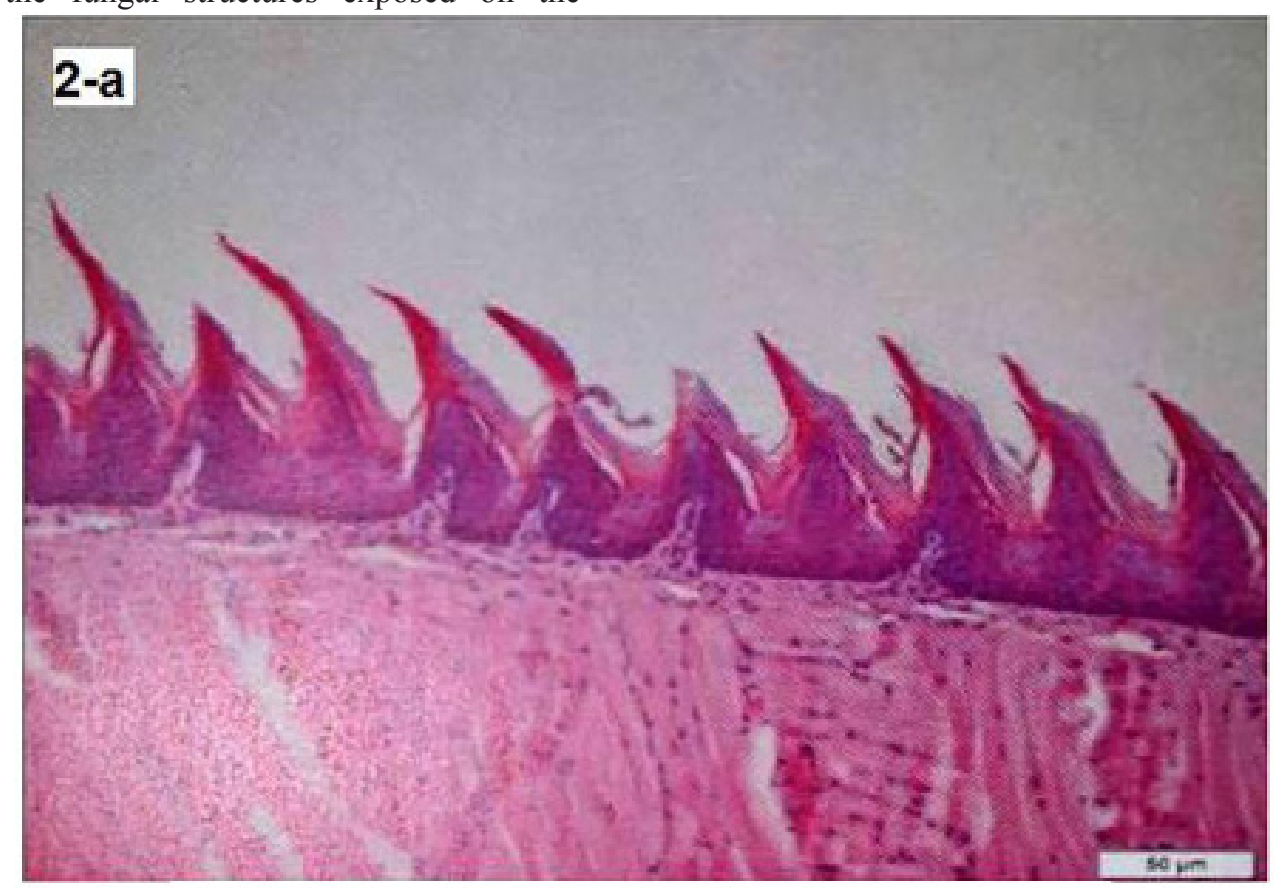

Photo 2-a. Sagittal section of the tongue dorsum of mice (control group), stained with $H \& E$ at magnification of $400 \mathrm{x}$, showing normal keratinized filiform papillae.

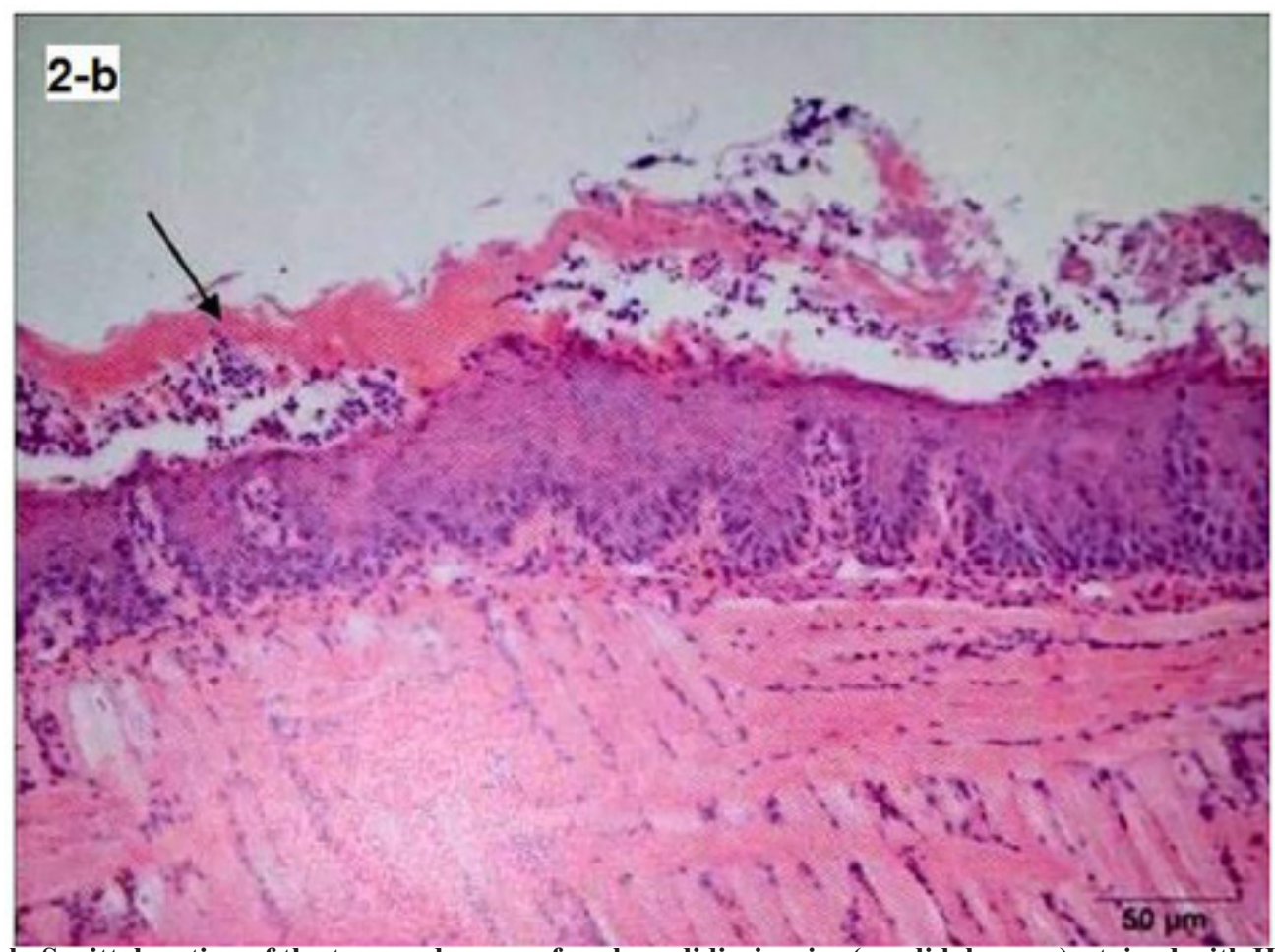

Photo 2-b. Sagittal section of the tongue dorsum of oral candidiasis mice (candidal group), stained with H\&E at magnification of $400 \mathrm{x}$, showing loss of filiform papillae with keratin layer regression. 


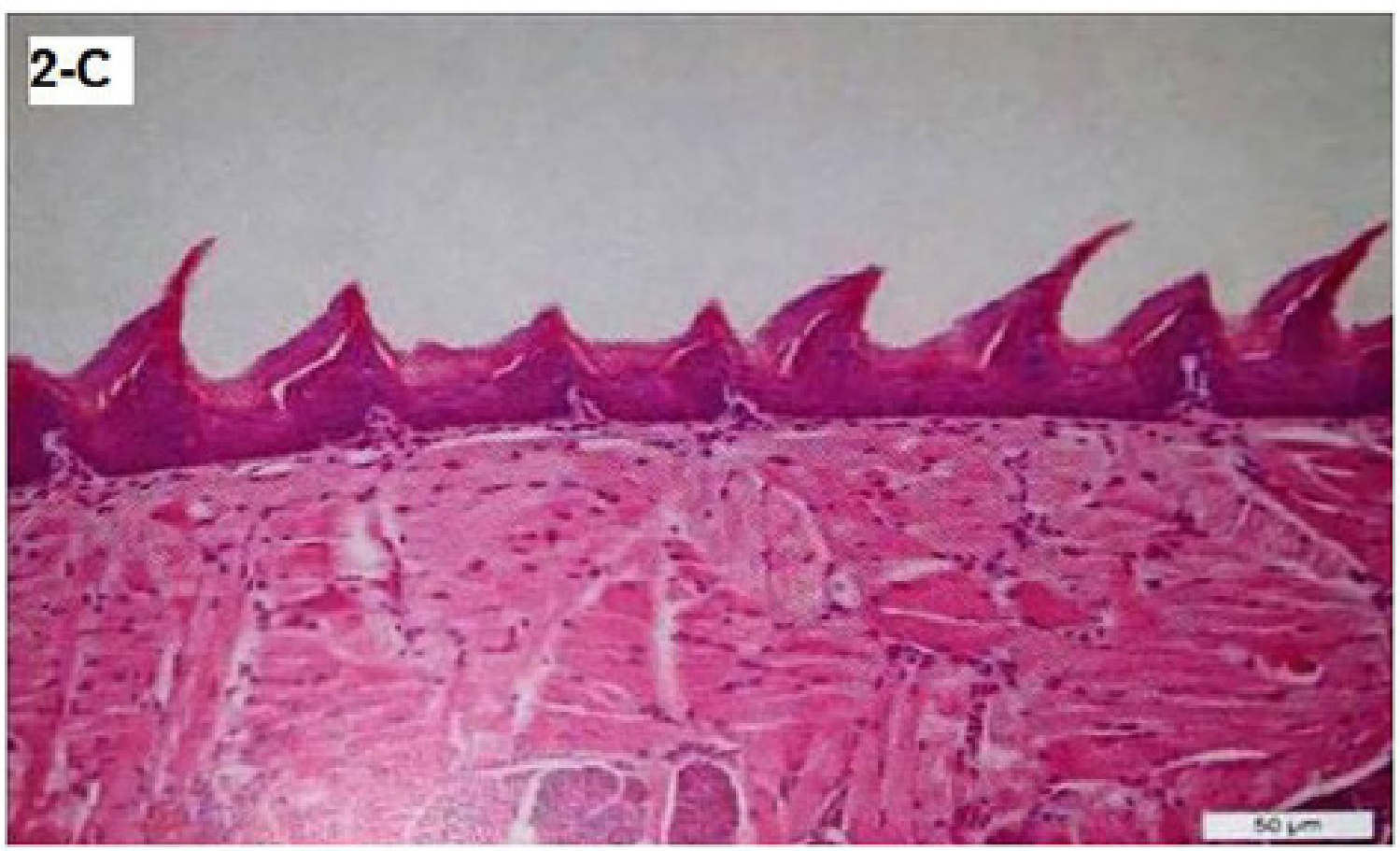

Photo 2-c. Sagittal section of the tongue dorsum of oral candidiasis mice (AgNPs group), stained with H\&E at magnification of $400 \mathrm{x}$, showing healthy filiform papillae covered by undamaged keratinized layer.

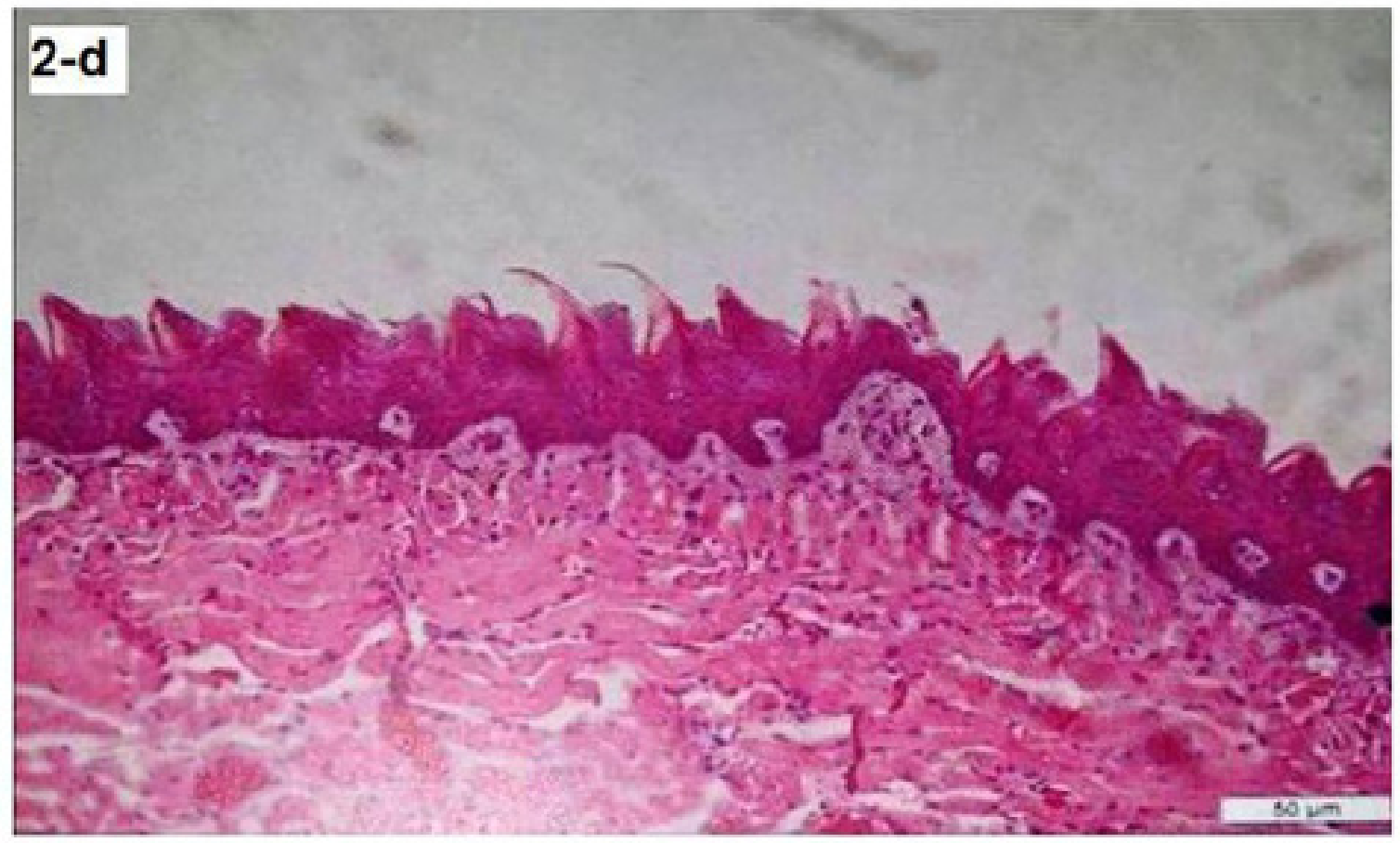

Photo 2-d. Sagittal section of the tongue dorsum of oral candidiasis mice (FLC/AgNPs treated group), stained with $H \& E$ at magnification of $400 \mathrm{x}$, showing recession keratinized layer and increased interpapillary surface with partial distortion of filiform papillae. 


\section{Conclusion}

Our investigation suggests that AgNPs alone or combined with fluconazole is safe to treat oral candidiasis, since it has antifungal activity without harming the host tissue. We recommend the use green silver nanoparticles against fluconazoleresistant Candida albicans in clinical trials.

\section{References}

Al-Mughrabi, K.I., Aburjai, T.A., Anfoka, G.H. and Shahrour, W. (2001) Antifungal activity of olive cake extracts. Phytopathologia Mediterranea, 40, (3), 240-244.

Awwad, A.M., Salem, N.M. and Abdeen, A.O. (2012) Biosynthesis of silver nanoparticles using Olea europaea leaves extract and its antibacterial activity. Nanoscience \& Nanotecnol. 2(6), 164-170 .

Bayraktar, H. Ghosh, P.S., Rotello, V.M. and Knapp, M.J. (2006) Disruption of protein-protein interactions using nanoparticles: Inhibition of cytochrome c peroxidase. Chem . Commun (Camb) 13, 1390-1392.

Bhinder, S.S. and Dadra, P. (2009) Application of nanostructures and new nano particles as advanced biomaterials. Asian. J. Chem. 21, S167-S171.

Chau, A.S., Mendrick, C.A., Sabatelli, F.J., Loebenberg, D. and McNicholas, P.M. (2004) Application of real-time quantitative PCR to molecular analysis of Candida albicans strains exhibiting reduced susceptibility to azoles. Antimicrob. Agents. Chemother. 48, 2124-2131.

Chen, L.M., Xu, Y.H., Zhou, C.L., Zhao, J., Li, C.Y. and Wang, R. (2010) Over expression of CDR1 and CDR2 genes plays an important role in fluconazole resistance in Candida albicans with G487T and T916C mutations. J. Int. Med. Res. 38, 536-545.

CLSI (2012) Clinical and Laboratory Standards Institute: Reference method for broth dilution antifungal susceptibility testing of yeasts. $4^{\text {th }}$ Informational Supplement. Document M27-S4. Wayne, PA.

Cowen, L.E., Anderson, J.B. and Kohn, L.M. (2002) Evolution of drug resistance in Candida albicans. Annu. Rev. Microbiol. 56, 139-165

Feng, Q.L., Wu, J., Chen, G.Q., Cui, F.Z., Kim, T.N. and Kim, J.O. ( 2000) A mechanistic study of the antibacterial effect of silver ions on Escherichia coli and Staphylococcus aureus. J. Biomed. Mater. Res. 52, 662-668.

Fischer, N.O., McIntosh, C.M., Simard, J.M. and
Rotello, V.M. (2002) Inhibition of chymotrypsin through surface binding using nano-particle based receptors. Proc. Natl. Acad. Sci. 99, 5018-5023.

Fling, M.E., Kopf, J.T., Amarkin, A., Gorman, J.A., Smith, H.A. and Koltin, Y. (1991) Analysis of a Candida albicans gene that encodes novel mechanism for resistance to benomyl and methotrexate. Mol. Gen. Genet. 227, 318-329.

Francois, L.M., Duncan, W. and Bemhard, H. (2013) Candida albicans pathogencitity mechanisms. Virulence, 4(2), 119 - 128.

Gavhane, A.J., Padmanabhan, P., Kamble, S.P. and Jangle, S.N. (2012) Synthesis of silver nanoparticles using extract of neem leaf and triphala and evaluation of their antimicrobial activities. Int. J. Pharm. Bio. Sci. 3(3), 88-100.

Gomez-Lopez, A ., Alastruey-Izquierdo, A ., Rodriguez, D., Almirante ,B., Pahissa, A., Rodriguez-Tudela, J.L. and Cuenca-Estrella, M. (2008) Prevalence and susceptibility profile of Candida metapsilosis and Candida orthopsilosis: Results from populationbased surveillance of Candidemia in Spain. Antimicrob Agents Chemother. 52, 1506-1509.

Gupta, A. and Silver, S. (1998) Silver as a biocide: Will resistance become a problem?. Nat. Biotechnol. (16), 888-890.

Herrera, M., Carrion, P., Baca, P., Liebana, J. and Castillo, A. (2000) In vitro antibacterial activity of glass-monomer cements. Microbios. 104, 141-148.

Hu, L., Du, X., Li, T.,Song, Y., Zai, S., Hu, X., Zhang, $\mathrm{X}$. and Li, M. (2015) Genetic and phenotypic characterization of Candida albicans strains isolated from infectious disease patients in Shanghai. J. Med. Microbiol. 64, 74-83.

Hwang, I.S., Lee, J. and Hwang, J.H. (2012) Silver nanoparticles induce apoptotic cell death in Candida albicans through the increase of hydroxyl radicals. FEBS, J. 279, 1327-1338.

Ishida, K., Cipriano, T.F. and Rocha, G.M. (2014) Silver nanoparticle production by the fungus Fusarium oxysporum: nanoparticle characterisation and analysis of antifungal activity against pathogenic yeasts. Mem Inst Oswaldo Cruz. 109, 220- 228.

Julian, R., Naglik, J.R. and Challacombe, S.J. ( 2003) Candida albicans secreted aspartyl proteinase in virulence and pathogenesis. Microbiol. Mol. Biol. Rev. 67, 400-428.

Kanhed, P., Birla, S., Gaikwad, S., Gade, A., Seabra, A.B., Rubilar, O., Duran, N. and Rai, M. (2014) In vitro antifungal efficacy of copper nanoparticles 
against selected crop pathogenic fungi. Materials Letters, 115, 13-17.

Kapoor, K., Rehan, M., Lynn, A.M. and Prasad, R. (2010) Employing information theoretic measures and mutagenesis to identify residues critical for drugproton antiport function in Mdrlp of Candida albicans. PLOSONE, 5, e11041.

Kaviya, S., Santhanalakshmi, J., Viswanathan, B., Muthumary, J. and Srinivasan, K. (2011) Biosynthesis of silver nanoparticles using citrus sinensis peel extract and its antibacterial activity. Spectro Chim Acta: Part A, 79, 594-598.

Kim, K.J., Sung, W.S. and Suh, B.K. (2009) Antifungal activity and mode of action of silver nano-particles on Candida albicans. Biometals, 22, 235-242.

Kristan, K. and Rizner, T.L. (2012) Steroid-transforming enzymes in fungi. J. Steroid Biochem. Mol. Biol. 129, 79-91.

Lilly, L.B. (2012) Drug-induced liver disease. In: "Hepatology: Diagnosis and Clinical Management". Heathcote, J. (Ed.), pp. 235-243. Wiley-Blackwell, Hoboken, NJ, US.

Lima, R., Feitosa, L.O. and Ballottin, D. (2013) Cytotoxicity and genotoxicity of biogenic silver nanoparticles. J. Physics. Conference Series, 429, 012020 .

Lukman, A.I., Gong, B., Marjo, C.E., Roessner, U. and Harris, A.T. (2011) Facile synthesis, stabilization, and anti-bacterial performance of discrete $\mathrm{Ag}$ nanoparticles using Medicago sativa seed exudates. J. Colloid Interface. 3(53), 433-444.

Maneewattanapinyo, P., Banlunara, W., Thammacharoen, C., Ekgasit, S and Kaewamatawong, T (2011) An evaluation of acute toxicity of colloidal silver nanoparticles. J. Vet. Med. Sci. 73, 1417-1423.

Marcato, P.D., Parizotto, N.V. and Martinez, D.S.T. (2013) New hybrid material based on layered double hydroxides and biogenic silver nanoparticles: Antimicrobial activity and cytotoxic effect. J. Braz. Chem. Society, 24, 266-272.

Matsumura, Y., Yoshikata, K., Kunisaki, S. and Tsuchido, T. (2003) Mode of bactericidal action of silver zeolite and its comparison with that of silver nitrate. Appl. Environ. Microbiol. 69, 4278-4281.

Monroy-Perez, T., Sainz-Espunes, G., PaniaguaContreras, E ., Negrete-Abascal, J., RodriguezMoctezuma, R. and Vaca, S. (2012) Frequency and expression of ALS and HWPI genotypes in Candida albicans strains isolated from Mexican patients suffering from vaginal candidiosis. Mycoses, 55, 151-157.

Narayanan, K.B. and Sakthivel, N (2011) Extracellular synthesis of silver nanoparticles using the leaf extract of Coleus amboinicus Lour. Mater. Res. Bull. 46, 1708-1713.

Odds, F.C., Brown, A.J. and Gow, N.A. (2003) Antifungal agents: mechanisms of action. Trends Microbiol. 11, 272-279.

Pfaller, M.A. (2012) Antifungal drug resistance: Mechanisms, epidemiology, and consequences for treatment. Am. J. Med. 125, S3-S13.

Pfaller, M.A. and Diekema, D.J. (2004) Rare and emerging opportunistic fungal pathogens: Concern for resistance beyond Candida albicans and Aspergillus fumigatus. J. Clin. Microbiol. 42(10), 4419-31.

Prasad, R. and Goffeau, A (2012) Yeast ATP-Binding cassette transport erscon-ferring multi-drug resistance. Annu. Rev. Microbiol. 39-63.

Sangetha, S., Zuraini, Z., Suryani, S. and Sasidharan, S. (2009) In situ TEM and SEM studies on the antimicrobial activity and prevention of Candida albicans biofilm by Cassia. spectabilis. extract. Micron. 40, 439-443.

Sanglard, D. (2002) Clinical relevance of mechanisms of antifungal drug resistance in yeasts. Enferm. Infecc. Microbiol. Clin. 20, 462-469.

Sanglard, D., Ischer, F., Koymans, L. and Bille, J. (1998) Amino acid substitutions in the cytochrome P-450 lanosterol 14 $\alpha$-demethylase (CYP51A1) from azoleresistant Candida albicans clinical isolates contribute to resistance to azole antifungal agents. Antimicrob. Agents Chemother. 42, 241-253.

Sastry, M., Ahmad, A., Islam, K.M. and Kumar, R. (2003) Bio- synthesis of metal nanoparticles using fungi and actinomycetes. Current Science, 85(2), 162-170.

Sheny, D.S., Mathew, J. and Philip, D. (2011) Phytosynthesis of $\mathrm{Au}, \mathrm{Ag}$ and $\mathrm{Au}-\mathrm{Ag}$ bimetallic nanoparticles using aqueous extract and dried leaf of Anacardiumo ccidentale. Spectro. Chim. Acta: Part A, 79, 254-262.

Shin, Y.J., Kwak, J.I. and An, Y.J. (2012) Evidence for the inhibitory effects of silver nanoparticles on the activities of soil exoenzymes. Chemosphere, 88, 524-529.

Solis, N.V. and Filler, S.G. (2012) Mouse model of oropharyngeal candidiasis. Nature Protocols, 7(4), $637-642$. 
SPSS, 14 (2006) Statistical Package for Social Science, SPSS for windows Release 14.0.0, 12 June, 2006. Standard Version, Copyright SPSS Inc., 19892006, All Rights Reserved, Copyright ${ }^{\circledR}$ SPSS Inc.

Takakura, N., Sato, Y., Ishibashi, H., Oshima, H., Uchida, K., Yamaguchi, H. and Abe, S. (2003) A novel murine model of oral candidiasis with local symptoms characteristic of oral thrush. Microbiol. Immunol. 47(5), 321-326.

Vidhu, V.K., Aromal, S.A. and Philip, D. (2011) Green synthesis of silver nanoparticles using Macrotyloma uniflorum. Spectro Chim Acta, Part A, 83, 392-397.

Vidotto,V., Ponton, J., Aoki, S., Quindos, G., Mantoan, B., Pugliese, A., Kuwa, S.I. and Nakamura, K. (2004) Differences in extracellular enzymatic activity between Candida dubiliensis and Candida albicans isolates. Rev. Iberoam. Micol., 21, 70-74.

Wu, Z., Zhang, B. and Yan, B. (2009) Regulation of enzyme activity through interactions with nanoparticles. Int . J. Mol. Sci. 10, 4198-4209.

Xia, Z.H., Ma, H.Q., Li, Y.S., De-Quan, Q.D., Cong, L., Tian, L.Y. and Yang, Y.R. ( 2016) The antifungal effect of silver nanoparticles on Trichosporon. asahii. J. Microbiol. Immunolo. Infection, 49, 182- 188.

Yu, D.G. (2007) Formation of colloidal silver nanoparticles stabilized by $\mathrm{Na}+$-poly (-glutamic acid) silver nitrate complex via chemical reduction process. Colloids and Surfaces B: Bio-interfaces, 59, 171-178.

(Received 4 / 7 /2017; accepted $13 / 1 / 2018$ )

\section{التاثير الضد ميكروبى لجزيئات الفضة النانونية الخضراء تجاه فطر الكانديا| المقاومة

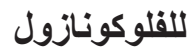

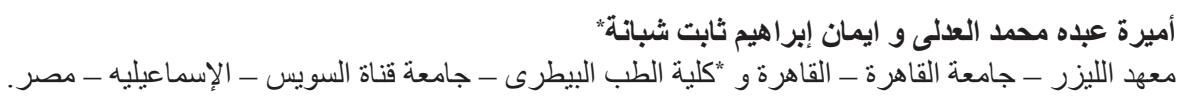

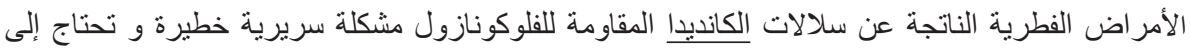

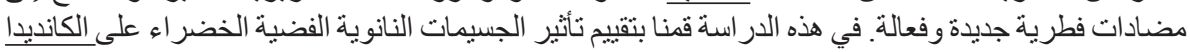

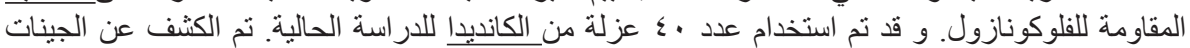

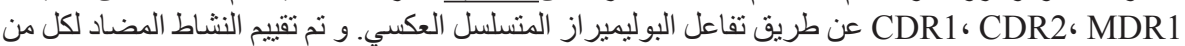

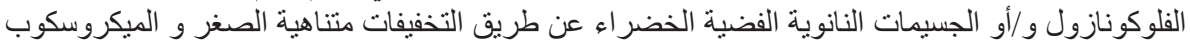

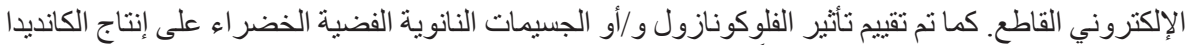

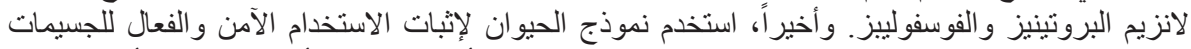

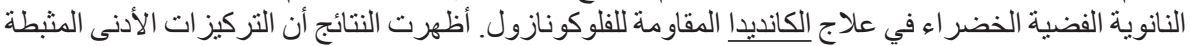

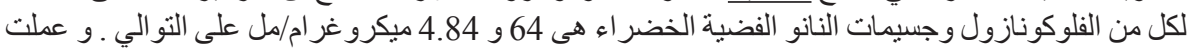

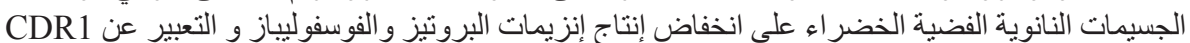

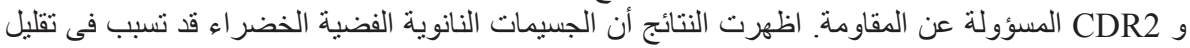

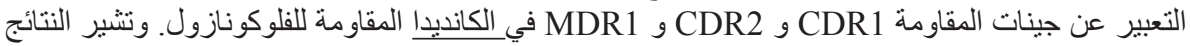

إلى استخدام الجسيمات النانوية الفضية الخضر اء كعلاج أمن وفعال ضد الكانديدا المقاومة للفلوكونازول. 